\title{
Turismo de base comunitária: \\ considerações conceituais e perspectivas de implementação em um bairro popular de Salvador-BA
}

Community based tourism: conceptual considerations and prospects for implementation in a popular neighborhood of Salvador-BA

Turismo de base comunitaria: consideraciones conceptuales y perspectivas de implementación en un barrio popular de Salvador $-B A$

http://dx.doi.org/10.18472/cvt.18n2.2018.1310

Paulo Henrique Oliveira Silva 〈paulo.turismo@yahoo.com.br >

Universidade Salvador (Unifacs), Salvador, BA, Brasil

Carolina de Andrade Spinola <cas.spinola@gmail.com >

Universidade Salvador (Unifacs), Salvador, BA, Brasil

CRONOLOGIA DO PROCESSO EDITORIAL

Recebimento do artigo: 11-jul-2016

Aceite: 12-mar-2018

FORMATO PARA CITAÇÃO DESTE ARTIGO

SILVA, P. H. O.; SPINOLA, C. A. Turismo de base comunitária: considerações conceituais e perspectivas de implementação em um bairro popular de Salvador-BA. Caderno Virtual de Turismo. Rio de Janeiro, v. 18, n. 2, p. 85-103, ago. 2018.

REALIZAÇÃO

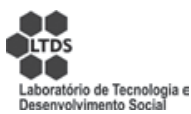

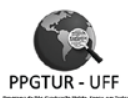

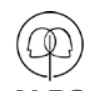

APOIO INSTITUCIONAL

EDIÇÃO

PATROCÍNIO

IABS

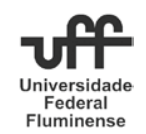




\section{RESUMO}

O objetivo deste artigo é apresentar as bases conceituais que fundamentaram a construção do conceito de Turismo de Base Comunitária, diferenciando-o da maneira convencional de se pensar a implementação da atividade e refletir sobre os desafios e possibilidades desse modelo em um bairro popular de Salvador, o bairro do Cabula. Do ponto de vista metodológico, o método de abordagem escolhido foi o indutivo, o método de procedimento foi o Estudo de Caso e a pesquisa de levantamento se constituiu no principal procedimento utilizado. Concluiu-se que a despeito do patrimônio cultural e natural autêntico e apropriado para a oferta do TBC, a comunidade local ainda não compartilha laços de confiança capazes de sustentar uma atividade cooperativa e tampouco seus moradores demonstram estoques suficientes de engajamento para atuarem como protagonistas de processos participativos.

Palavras-chave: Turismo de Base Comunitária. Políticas Públicas. Cabula.

\section{ABSTRACT}

The purpose of this article is to present the conceptual bases that supported the construction of the concept of Community Based Tourism, differentiating it from the conventional way of thinking about the implementation of the activity and reflecting on the challenges and possibilities of this model in a popular neighborhood of Salvador, Cabula. From the methodological point of view, the method of approach chosen was the inductive one, the procedure method was the Case Study and the survey was the main procedure used. It was concluded that in spite of the authentic and appropriate natural and cultural patrimony for the TBC offer, the local community still does not share the trust ties capable of sustaining a cooperative activity and neither do its inhabitants demonstrate sufficient stocks of engagement to act as protagonists of participatory processes.

Keywords: Community Based Tourism. Public Policies. Cabula.

\section{RESUMEN}

El objetivo de este artículo es presentar las bases conceptuales que fundamentaron la construcción del concepto de Turismo de Base Comunitaria, diferenciándolo de la manera convencional de pensar la implementación de la actividad y reflexionar sobre los desafíos y posibilidades de este modelo en un barrio popular de Salvador, el barrio de Cabula. Desde el punto de vista metodológico, el método de abordaje elegido fue el inductivo, el método de procedimiento fue el Estudio de Caso y, además, se utilizó de entrevistas y cuestionarios. Se concluyó que a pesar del patrimonio cultural y natural auténtico y apropiado para la oferta del TBC, la comunidad local aún no comparte lazos de confianza capaces de sostener una actividad cooperativa y tampoco sus habitantes demuestran un compromiso suficiente para actuar como protagonistas de procesos participativos.

Palavras clave: Turismo de Base Comunitaria. Políticas Públicas. Cabula. 


\section{INTRODUÇÃO}

Este artigo inicia-se com um paradoxo: o setor de serviços em geral e o turismo, em particular, tem sido visto, ao longo das últimas décadas, como a melhor oportunidade e a opção mais viável para o desenvolvimento sustentável das regiões mais pobres dos países; todavia, tradicionalmente, o fluxo de viagens que se dirige a essas regiões canaliza a maior parte das receitas para os países de origem dos visitantes, não gerando os resultados esperados. De acordo com estudos do Overseas Development Institute, às localidades-destino, cabem, em média, apenas 30\% de tudo o que é gerado por essa indústria. (ASHLEY; GOODWIN, 2007).

As políticas públicas para o turismo podem e devem focar em ações específicas capazes de solucionar esse paradoxo, e é justamente com esse objetivo que se fortaleceu a ideia do Turismo de Base Comunitária (TBC).

O TBC, apesar de, na prática, não ser uma novidade, se tornou, nos últimos anos, o novo protagonista das políticas públicas de promoção do desenvolvimento baseadas no turismo e de pesquisas e experiências da academia voltadas para o mesmo fim. Fundamentado em estudos que priorizam a abordagem das comunidades e as suas relações sociais, culturais e econômicas com o fenômeno turístico, o TBC se apresenta como um novo paradigma da atividade, que se opõe ao modelo tradicional de organização do setor, concentrador e excludente.

O objetivo deste artigo é apresentar as bases conceituais que fundamentaram a construção do conceito de Turismo de Base Comunitária, diferenciando-o da maneira convencional de se pensar a implementação da atividade e investigar o seguinte problema: quais são os desafios e possibilidades de implementação do TBC no Bairro do Cabula, em Salvador-BA?

Do ponto de vista metodológico, o método de abordagem escolhido foi o indutivo, o método de procedimento foi o Estudo de Caso e a pesquisa de levantamento se constituiu no principal procedimento utilizado, tendo sido consultados 100 moradores do Cabula, entre os meses de abril e junho de 2014.

O presente artigo está organizado em quatro seções, além desta Introdução. Na primeira, apresentase a construção teórica do paradigma TBC e os seus desafios; na segunda sessão apresenta-se a realidade do bairro estudado; na terceira parte são descritos os procedimentos metodológicos e os resultados da pesquisa de campo e, por fim, na quarta e última sessão tecem-se as considerações finais.

\section{Turismo de Base Comunitária: a Construção Teórica de um novo paradigma na indústria das viagens}

A ideia de turismo de base comunitária representa um novo paradigma na indústria de viagens. Longe de se constituir em mais um modismo ou uma nova segmentação, baseia-se em premissas teóricas claras e diferenciadas da prática convencional, situando essa nova abordagem, em tese, como uma alternativa que atende às premissas do turismo pós-moderno.

Apesar da recente popularidade que o termo passou a desfrutar, tanto em publicações científicas quanto em documentos governamentais, é importante destacar que a sua construção teórica não se deu da noite para o dia, tendo sido fruto de um processo lento, que absorveu inúmeras contribuições, oriundas da academia e da prática cotidiana de algumas comunidades tradicionais pioneiras, que hoje servem de exemplo, como casos a serem estudados. 
No que tange às ações de organismos multilaterais e de fomento, o conceito de TBC evoluiu do que, a partir dos anos 1970, ficou internacionalmente conhecido como Community Based Tourism - CBT para, mais tarde, na década de 1990, o que se convencionou denominar de Pro-Poor Tourism. ${ }^{1}$ Para muitos autores e gestores de programas governamentais ao redor do mundo, tratam-se de sinônimos. Todavia, para Goodwin (2006) e Scaglione, Marx e Johnson (2011), o Pro-Poor Tourism² é uma evolução do conceito de Community Based Tourism ${ }^{3}$ na medida em que mantém os mesmos pressupostos filosóficos relacionados com o protagonismo da comunidade, a baixa escala da operação e a sustentabilidade das ações, mas avança no sentido de viabilizar essas iniciativas que, em sua maioria, ao longo das décadas de 1970 e 1980, falharam na consecução de seus objetivos ${ }^{4}$.

Throughout the years, a number of CBT projects have been implemented in developing countries, but their success has not been widely monitored. Questions remain regarding the actual involvement and participation of the vulnerable and generally poor communities in these initiatives. In many cases CBT projects have failed to deliver financial viability due to lack of trade-off between costs and revenues, commercially unsustainable products, and weak market linkages, hence weak market demand. (MARX, 2011, p. 1)

A abordagem do Pro-Poor Tourism é mais pragmática e, sem prejuízo das suas bases filosóficas, objetiva estimular os encadeamentos verticais (atividades de alojamento, alimentação, excursões, artesanato, produção associada ao turismo, etc.) e horizontais (relações formais e informais com outros setores da economia, tais como o de serviços e comércio em geral) da atividade turística. Atuando dessa forma, seus defensores alegam obter maior capilaridade nos resultados alcançados, tendo em vista mobilizar um maior número de atores locais e, com isso, maximizar os efeitos multiplicadores da atividade na economia do destino.

De fato, as duas abordagens enfatizam aspectos distintos do que hoje se entende ser o TBC. Enquanto a primeira privilegia a preocupação com o matiz sociocultural dos projetos, com que haja uma preocupação real com o protagonismo da comunidade e a autenticidade da experiência, a segunda abordagem parte do princípio de que nada disso será efetivo e se constituirá em um retorno válido para a região-destino, se não for bem pensado enquanto produto e, como tal, comercializado por meio da cadeia produtiva do turismo. As diferenças entre essas duas vertentes, por sua vez, foram baseadas no arcabouço teórico que se construiu em torno do tema.

O arcabouço teórico que fundamenta as formulações do TBC teve origem na década de 1970, quando a corrente desenvolvimentista das pesquisas em turismo emergiu, principalmente composta por antropólogos e geógrafos, direcionando seus estudos para os impactos da atividade nas comunidades-destino, ao tempo em que desenvolvia a argumentação de base para o futuro binômio: turismo x desenvolvimento. Entre os autores cujos trabalhos mais contribuíram para o surgimento desse novo paradigma estão MacCannel (1973), Doxey (1975), De Kadt (1979) e Plog (1977).

\footnotetext{
1 Designação cunhada, em 1999, pelo Departamento de Desenvolvimento Internacional da Grã-Bretanha. 2 Definido originalmente como o "turismo que resulta no aumento dos benefícios (financeiros) líquidos (da atividade) para as pessoas pobres”. (PRO POOR TOURISM PARTNERSHIPS apud ROE, 2006) (Tradução própria).

3 Entendido como "Visitação econômica, ambiental, social e culturalmente responsável a comunidades locais/indígenas para desfrutar e apreciar sua herança natural e cultural, cujos produtos e serviços turísticos são desenvolvidos e gerenciados com a sua participação ativa, e seus benefícios, tangíveis ou não, são coletivamente desfrutados pelas comunidades" (BOONRATANA, 2010, p. 286) (Tradução própria).

4 "Ao longo dos anos, um grande número de projetos de CBT foram implantados em países em desenvolvimento, mas o seu sucesso não tem sido convenientemente monitorado. Questões relacionadas com o real envolvimento e participação das comunidades nessas iniciativas, geralmente pobres e vulneráveis. Em muitos casos, projetos de CBT falharam ao não garantir viabilidade financeira, por apresentar produtos comercialmente insustentáveis e fracas conexões com o mercado" (MARX, 2011, p. 1) (Tradução própria).
} 
Dean MacCannell, em seu artigo, "Staged Authenticity: Arrangements of Social Space in Tourist Settings", acredita que os turistas contemporâneos (percebam que ele se referia à contemporaneidade da década de 1970) não buscam apenas o prazer, mas estão em uma missão na busca pela autenticidade. Em um trabalho posterior, de 1976, "The tourist: a new theory of leisure class", MacCannell torna a abordar a questão da autenticidade ao propor que os destinos turísticos se dividem em regiões de "frente" e de "fundo".

As regiões de "frente" seriam aquelas que, obviamente, são apresentadas aos turistas, enquanto as de "fundo" se referem às áreas onde os moradores vivem sua rotina cotidiana. Para o autor, estas últimas são o objeto de desejo do turista contemporâneo ${ }^{5}$.

Touristic shame is not based on being a tourist but on not being tourist enough, on a failure to see everything the way it 'ought' to be seen. The touristic critique of tourism is based on a desire to go beyond the other 'mere' tourists to a more profound appreciation of society and culture, and it is by no means limited to intellectual statements. All tourists desire this deeper involvement with society and culture to some degree; it is a basic component of their motivation to travel (MacCANNELL, 1976, p. 10).

A síntese do argumento de MacCannell é que o turista que foge da rota traçada pelas operadoras, que abomina a exploração e as armadilhas turísticas óbvias é o turista superlativo (SCHUDSON, 1979, p. 1251). ${ }^{6}$

It is assumed that the back is the area of the authentic and untouched and is thus especially interesting for tourists as it embodies the 'real' life and not a simple 'show' (MacCANNELL, 1973, p.10).

Uma grande questão levantada por ele é a falsa autenticidade, que consistiria na reprodução espetacularizada do modo de vida das comunidades em áreas de "frente" com a intenção de iludir os turistas. A discussão sobre autenticidade mostrou-se um pilar teórico fundamental para as propostas do TBC, pois ao se pretender trabalhar com comunidades, os limites da intervenção do pesquisador/gestor público devem ser bem estabelecidos e monitorados. O autêntico é natural e como tal deve ser permitido que se expresse.

Doxey (1975) por meio do seu clássico "Modelo Irridex" ao descrever os estágios pelos quais passa a relação turista $\mathrm{x}$ residente ${ }^{7}$ revelou os impactos socioculturais oriundos da prática da atividade que determinam uma mudança na atitude dos moradores em relação aos visitantes. Essa discussão tem relação com a escala em que o turismo é praticado e com o nível de envolvimento da comunidade nesse processo. Quanto maior a densidade da visitação e quanto menor o protagonismo da comunidade na determinação desses limites e no gerenciamento dos eventuais impactos dele decorrentes, maior deve ser o antagonismo estabelecido entre os dois públicos.

De Kadt (1979) destacou a importância do turismo na economia analisando os seus efeitos para trás e para frente em relação a outras atividades econômicas e o estímulo que traz ao empreendedorismo. Essa contribuição é importante no momento em que consideramos que o TBC demanda um grande efeito multiplicador da produção do turismo e aciona a cadeia produtiva local por meio do estímulo

5 A vergonha do turista não está baseada em ser um turista, mas em não ser turista o suficiente, na falha de ver tudo do jeito que elas "devem" ser vistas. A crítica turística ao turismo é baseada no desejo de ir mais além do que os outros turistas, na direção de uma apreciação mais profunda da sociedade e da cultura. Todos os turistas desejam esse envolvimento mais profundo com a cultura e a sociedade em algum grau; este é um componente básico de suas motivações para viajar. (MacCANNELL, 1976, p. 10). (Tradução nossa)

6 Assume-se que área de "fundo" é a área autêntica, intocada e especialmente interessante para os turistas na medida em que eles percebem a vida real e não apenas um show. (MacCANNELL, 1999) (Tradução nossa).

7 De acordo com esse modelo, a relação turista $x$ residente, notadamente em localidades pequenas, se modifica substancialmente em função do próprio desenvolvimento da atividade, passando pelos estágios de euforia, apatia, irritação e antagonismo. 
aos pequenos empreendedores de negócios relacionados com a produção associada ao turismo. No que tange ao aspecto sociocultural, De Kadt (1979) analisou as circunstâncias nas quais os turistas e residentes se encontram e as possíveis situações de conflito derivadas dessas circunstâncias, tanto de natureza econômica como sociocultural. Para ele, o encontro entre turistas e moradores ocorre em três contextos principais: a) Quando o turista compra um bem ou serviço do residente; b) Quando ambos compartilham o mesmo espaço físico (praias, passeios, etc.) e c) Quando ambos trocam informações e/ou ideias.

Em relação aos dois primeiros, a grande incidência de visitantes em uma localidade pequena reforça os efeitos indesejáveis já descritos por Doxey, pois uma grande demanda encarece os produtos e serviços que são consumidos pela população e acentua a disputa por espaço físico, notadamente pelos espaços de lazer utilizados pela comunidade. Como afirmam Mathieson e Wall (1982, p. 121), "O turismo de massa está rodeado, mas não integrado na sociedade receptora" favorecendo situações em que a segregação dos moradores em seu próprio território torna-se uma realidade inevitável.

O terceiro contexto é menos comum, observável, muitas vezes, apenas nas localidades que desenvolvem modalidades de turismo próximas da proposta do TBC, pois depende de um contato mais próximo e demorado entre os dois interlocutores. Essa troca de informações e esse conhecimento mútuo é justamente o que almeja o turista superlativo de MacCannell.

A contribuição de Plog (1977) para essa discussão foi justamente a de identificar os diferentes perfis dos turistas e suas motivações. Em sua obra ele identificou cinco tipos que variam entre dois extremos, em uma escala ${ }^{8}$. Nesses extremos estão os turistas chamados de psicocêntricos e alocêntricos. O primeiro grupo gostaria de viajar para locais conhecidos, e não seria afeito à experimentação, não se adaptaria facilmente a novos costumes e necessitaria de uma infraestrutura apropriada para lhe dar sensação de segurança. Já o segundo grupo se sentiria atraído por novos destinos desconhecidos, nos quais predominam o original, o genuíno e o autêntico. Esse é o tipo que corresponderia, na formulação de Plog, ao público do TBC.

Mais recente, e seguindo a mesma vertente dos estudos mencionados, merece destaque a contribuição do economista marroquino Hassan Zaoual sobre a teoria dos sítios simbólicos de pertencimento que reivindica a busca por um turismo mais situado, em oposição à hegemonia do tradicional turismo de massa. (ZAOUAL, 2003, 2006). A contribuição de Zaoual corrobora o surgimento do que Poon (1993) definiu como Nova Era do Turismo, uma fase em que, entre outras características, coexistiriam os dois paradigmas norteadores da indústria: o tradicional ou de massa e aquele considerado alternativo, representado, entre outras manifestações, pelo turismo de base comunitária.

Outra corrente de contribuições teóricas para o construto do TBC vem dos estudos nas áreas da economia regional e da geografia do desenvolvimento ao se associá-lo a uma estratégia de desenvolvimento endógeno que se propõe a

atender às necessidades e demandas da população local através da participação ativa da comunidade envolvida. Mais do que obter ganhos em termos da posição ocupada pelo sistema produtivo local na divisão internacional ou nacional do trabalho, o objetivo é buscar o bem-estar econômico, social e cultural da comunidade local em seu conjunto. Além de influenciar os aspectos produtivos (agrícolas, industriais e de serviços), a estratégia de desenvolvimento procura também atuar sobre as dimensões sociais e culturais que afetam o bem-estar da sociedade.

8 Alocêntricos, para-alocêntricos, cêntricos, parapsicocêntricos e psicocêntricos. Segundo Plog (1977), os cêntricos correspondem à maioria. 
O desenvolvimento endógeno é uma nova abordagem da teoria do desenvolvimento que privilegia a escala local, a mobilização de recursos produtivos disponíveis na comunidade e pela comunidade. Ao enfatizar o protagonismo comunitário, a teoria do desenvolvimento endógeno se aproxima da proposta do TBC e aciona outros conceitos derivados, necessários à sua consecução, a exemplo de empoderamento (empowerment ${ }^{9}$ ), economia solidária e enraizamento (embeddedness ${ }^{10}$ ) (BARQUERO, 2002, p. 39)

A base econômica que propicia esse processo alternativo de desenvolvimento pretende ser justa, sustentável e democrática ao optar pela via dos recursos próprios da região, também vinculada aos valores socioculturais da comunidade. No TBC, incluem-se, aí, as cooperativas e associações de artesãos, condutores de visitantes, pequenos produtores rurais, entre outras iniciativas de cunho solidário.

Como visto, o concurso praticamente simultâneo de todas essas influências, e de outras tantas que podem ter sido deixadas de fora por essa breve revisão, contribuiu para a formação do paradigma do TBC. Como resultado de todas essas influências, consideramos que as experiências de Turismo de Base Comunitária para, de fato, se processarem necessitam observar três características básicas ${ }^{11}$ : se constituírem em experiências autênticas, que proporcionem o conhecimento do cotidiano real de uma dada comunidade e, como tal, chegamos à segunda característica, que é o envolvimento de pessoas reais, dos moradores e suas redes de relações. Por fim, há de se proporcionar convivência e troca entre os visitantes e os visitados em um ambiente em que os saberes tradicionais são valorizados e que os turistas verdadeiramente desejam esse contato mais próximo com os anfitriões.

Todas essas características aludem para um modelo que, necessariamente, fundamenta-se no protagonismo comunitário e na cooperação. O protagonismo comunitário somente é conseguido através de um processo de empoderamento social em que os moradores locais, progressivamente, assumam o controle político e econômico das decisões que interferem em sua forma de vida e determinam os caminhos futuros da realidade que desejam para si e para os seus. Sendo comunitário, trata-se de um processo de identificação dos moradores com o lugar em que vivem e de articulação e mobilização de todos os envolvidos em prol de um beneficio comum. A existência desses fundamentos é o que se procurou verificar no estudo do bairro do Cabula.

\section{Cabula: apresentação do espaço estudado}

O bairro do Cabula localiza-se no centro geográfico de Salvador e é um dos bairros que compõem o conhecido Miolo da Cidade, conforme mostra a Figura 1. Os primeiros habitantes da área que deu origem ao bairro foram os índios tupinambás, seguidos dos africanos.

\footnotetext{
90 conceito de empoderamento pode ser abordado no âmbito do indivíduo e de seu processo pessoal de conquista de autonomia ou, como abordado aqui, na escala comunitária, representando o ganho crescente e continuado de controle das pessoas, enquanto coletividade, sobre as circunstâncias que determinam o futuro de suas vidas.

10 Embeddedness (ou enraizamento) é o grau em que os indivíduos ou firmas estão envolvidos em uma rede social. 0 conceito foi introduzido pelo sociólogo Mark Granovetter e envolve a sobreposição entre laços sociais e econômicos. (GRANOVETTER, 1985). 11 Há outras características citadas pela literatura, como a necessidade de se organizar como uma atividade econômica complementar, mas, neste artigo, destacamos as que consideramos mais fundamentais, notadamente no que se refere aos desafios impostos para a sua implementação.
} 


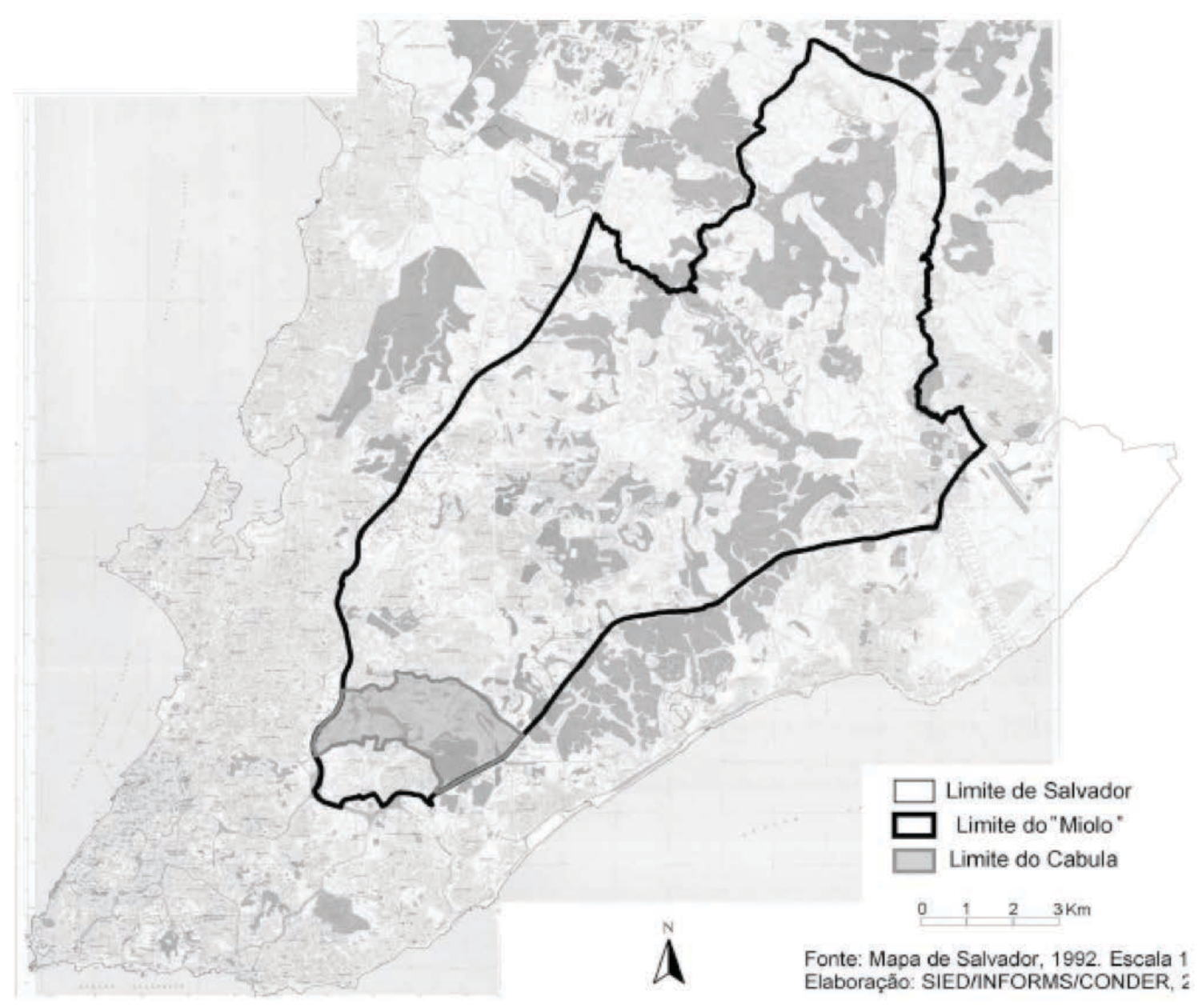

Figura 1 - Localização do Cabula - Centro Geográfico de Salvador

Fonte: Fernandes (2005)

O termo "Cabula" tem origem no idioma Bantu, falado em uma região africana situada entre os atuais países do Congo e Angola, e significa mistério, culto religioso, secreto e escondido (FERNANDES, 2003). É também o nome pelo qual foi chamada, no estado da Bahia, uma religião sincrética que passou a ser conhecida pelo seu caráter secreto, com o fim da escravidão, no final do século XIX. Tratava-se de uma prática afrocatólica, envolvendo correlação entre imagens de santos católicos com os Orixás, herança da fase reprimida nas senzalas dos cultos africanos, onde os antigos sacerdotes mesclavam suas crenças e culturas com o catolicismo para conseguirem praticar e perpetuar sua fé (NICOLIN, 2007).

No final do século XIX, com a libertação dos escravos, a religião Cabula já era amplamente presente entre a população afro-brasileira de Salvador. Na época, o ritual deveria ser mantido em segredo, por pacto feito entre eles. Há inúmeros fatos ligados aos adeptos, como prisões e torturas para que revelassem os segredos religiosos. A longevidade da religião Cabula ocorreu, inclusive, por conta desse pacto da sociedade negra com a sua religião (NICOLIN, 2007). As perseguições vinham desde a época em que era um culto velado, pois a Cabula era usada pelos negros como força de resistência. 
$\mathrm{Na}$ grande área do atual bairro do Cabula localizaram-se diversos quilombos, com destaque para o Quilombo do Cabula, famoso pela sua importância nos acontecimentos revolucionários da época. Ele era conhecido por localizar-se em uma área de grande riqueza natural, em meio à densa Mata Atlântica, o que favorecia a existência de esconderijos por meio da construção de postos de vigilância, de proteção territorial (SILVA, 2010).

Em quilombos como o Cabula que os ancestrais africanos recriaram a África. Para ilustrar a relação entre o bairro e os cultos de matriz africana (SILVA, 2014), vale acrescentar que "o primeiro registro baiano da palavra candomblé, designando um local de culto africano, foi em 1826, em um documento policial que se referia precisamente a um terreiro no Cabula" (FERNANDES, 2003, p. 169). Como reflexo de tal dado, pode-se perceber, ainda nos dias de hoje, a presença significativa de diversos terreiros de candomblé no bairro.

Ao longo de sua história, o Cabula foi sofrendo transformações significativas, notadamente a partir da década de 1990, quando o capital imobiliário avançou de maneira mais impactante. Como consequência, acelerou-se a construção de condomínios fechados, a degradação dos remanescentes de Mata Atlântica, a pulverização dos seus aspectos tradicionais e culturais e a atração de uma nova classe econômica (classe média), marcando assim uma nova fase para o bairro (GOUVEIA, 2010).

Tais mudanças ocasionaram novas funções à configuração urbana para o Cabula, que se tornou local de intenso comércio, com muita oferta de residências, densidade populacional, trânsito, presença de repartições públicas, entre outras características que o configuram como bairro heterogêneo. (GOUVEIA, 2010).

O Cabula é conhecido hoje por ser uma área residencial e de comércio pujante, porém, existem evidências que reforçam sua importância para a cultura regional, a singularidade e os valores sociais do Brasil. O cenário hoje é de um bairro que guarda pouco dessas memórias, com apenas algumas áreas remanescentes de Mata Atlântica preservadas por instituições locais ${ }^{12}$ e terreiros de candomblé com a sua memória oral. Portanto, trata-se de uma relevância simbólica com práticas musicais, religiosas e artísticas que serviram de matéria-prima para o TBC, e por ele poderiam ser protegidas e legitimadas (SILVA, 2010).

De acordo com Silva (2014), no bairro também existe o Projeto de Turismo de Base Comunitária da Universidade do Estado da Bahia (Uneb), que atua há, aproximadamente, seis anos. Para a autora, a principal motivação para trabalhar com Turismo de Base Comunitária no Cabula surgiu, basicamente, pela percepção de que as comunidades do entorno e a Uneb não interagiam de forma satisfatória e concluise que havia necessidade de reverter esse quadro de desarticulação.

A partir daí os primeiros estudos do projeto começaram nos âmbitos de ensino e extensão para posteriormente migrarem para a área da pesquisa e se consolidarem como um projeto que atenderia o Cabula e o seu entorno. O projeto é multidisciplinar e contempla 14 eixos temáticos em 17 bairros que compõem o que eles consideram como a grande região do Cabula. Atualmente, todos os objetivos do projeto estão focados no que a comunidade apresenta como legítimo.

12 Existem áreas que preservam a Mata Atlântica no bairro, como $019^{\circ} \mathrm{BC}\left(2.000 .000 \mathrm{~m}^{2}\right)$ e o restaurante Paraíso Tropical (60.000 $\mathrm{m}^{2}$ ). Áreas ligadas a cultos de origem africana destacam-se nessa preservação, como o Terreiro llê Axé Opô Afonjá (39.000 m²), a Casa de Lua Cheia $\left(7.000 \mathrm{~m}^{2}\right)$, o Terreiro Viva Deus $\left(\square 2.000 \mathrm{~m}^{2}\right)$ e o Terreiro Bate Folha (155.000 m²). 
O projeto já trouxe inúmeros benefícios, destacando: a) o lançamento do livro escrito por uma moradora, sobre a história do Terno de Reis Rosa Menina, do bairro de Pernambués; b) os novos canais de comunicação criados no bairro como o portal www.tbc.uneb.br; c) uma série de eventos relacionados com o Turismo de Base Comunitária, a Produção Associada ao Turismo e a Economia Solidária; d) o aumento do nível de participação e de instrução dos moradores, por meio do fomento promovido pelo projeto; e) a constituição do Cultart que é uma Associação de Artesanato que engloba pessoas dos 17 bairros; f) visitas técnicas às comunidades e melhoramento da imagem da Uneb na comunidade (SILVA, 2014).

\section{Desafios e Possibilidades do TBC: uma análise no bairro do Cabula em Salvador- BA}

Conforme discutido nas seções anteriores, o Turismo de Base Comunitária é um modo de fazer turístico novo e desponta como uma alternativa para locais até então desinteressantes para o turismo tradicional. Nesse caso, o nosso objeto de estudo é o Bairro do Cabula, e ao analisar as possibilidades e desafios para o desenvolvimento de projetos de TBC nessa comunidade foi necessário considerar a existência de atrativos turísticos capazes de gerar um fluxo de $\mathrm{TBC}$, as formas de relacionamento dos moradores com o território escolhido, assim como a existência de laços comunitários fortes entre os membros dessa mesma comunidade.

A pesquisa foi realizada no período de abril a julho de 2014, quando aplicaram-se questionários com os moradores do bairro, utilizando-se de uma amostra calculada com base na população da área demarcada na Figura 2, que era de aproximadamente 24.000 habitantes (SANTOS et al., 2010).

Utilizou-se uma distribuição de probabilidade binomial, o que pode ser simplificado através da probabilidade de ocorrer e de não ocorrer um fenômeno, $\mathrm{p}$ = probabilidade de ocorrer e $\mathrm{q}$ = probabilidade complementar ou de não ocorrer. $\mathrm{P}+\mathrm{q}=100 \%$. O que torna uma população homogênea ou não é o tipo de problema ou característica que buscamos ou que pesquisamos (GOMES, 2014). A fórmula para calculá-la ficou então definida como:

$$
n=\frac{\Theta^{2} \cdot p \cdot q}{e^{2}}
$$

. População homogênea implica em $\Theta=1$. Probabilidade de acontecer algo desconhecido $\mathrm{p}=50 \%$. Probabilidade complementar $\mathrm{q}=50 \%$. Erro máximo admitido e $=5 \%$ (caso escolar) 50.50/25 $=$ 100.

Foram aplicados 100 questionários, com 62 questões e divididos em três partes. A primeira parte aborda a percepção dos moradores sobre bairro e o seu nível de conhecimento acerca da sua formação e herança africana; na segunda parte, busca-se verificar o nível de interesse que a atividade turística desperta nesse público, enquanto uma atividade que possa ser fomentada no bairro; e, por fim, na terceira parte, abordam-se os laços comunitários existentes e o nível de engajamento dos moradores em assuntos que dizem respeito à sua comunidade. 
A amostra pesquisada caracteriza-se como sendo, em sua maioria, do gênero feminino (54\%), e constituída pelas faixas etárias de 41-50 anos (26\%) e 51-60 anos de idade (21\%). No que se refere à renda média, o maior registro ficou entre as pessoas que ganhavam de 1 a 3 salários mínimos (41\%). ${ }^{13}$ Já quanto à escolaridade, o "ensino médio completo" predominou com 43\% dos entrevistados. Sobre o tempo de residência, a maioria pode ser considerada como composta por moradores antigos, residindo no Cabula entre "21-30 anos" e de "31-40 anos" (22\% cada um dos grupos).

A primeira pergunta buscou entender a percepção dos moradores sobre o bairro a partir da memória afetiva dos entrevistados. Então, questionou-se o que o nome "Cabula" lhes evocava. As respostas mais representativas quantitativamente aludiam à ideia de um "Lugar bom de se morar" (30\%). Essa resposta foi justificada, segundo eles, pela "Tranquilidade" (10\%), "Localização privilegiada" (8\%), por ser um "Bairro em crescimento" (7\%), "Convívio com a natureza" e "Herança africana" (6\%), conforme a Figura 2.

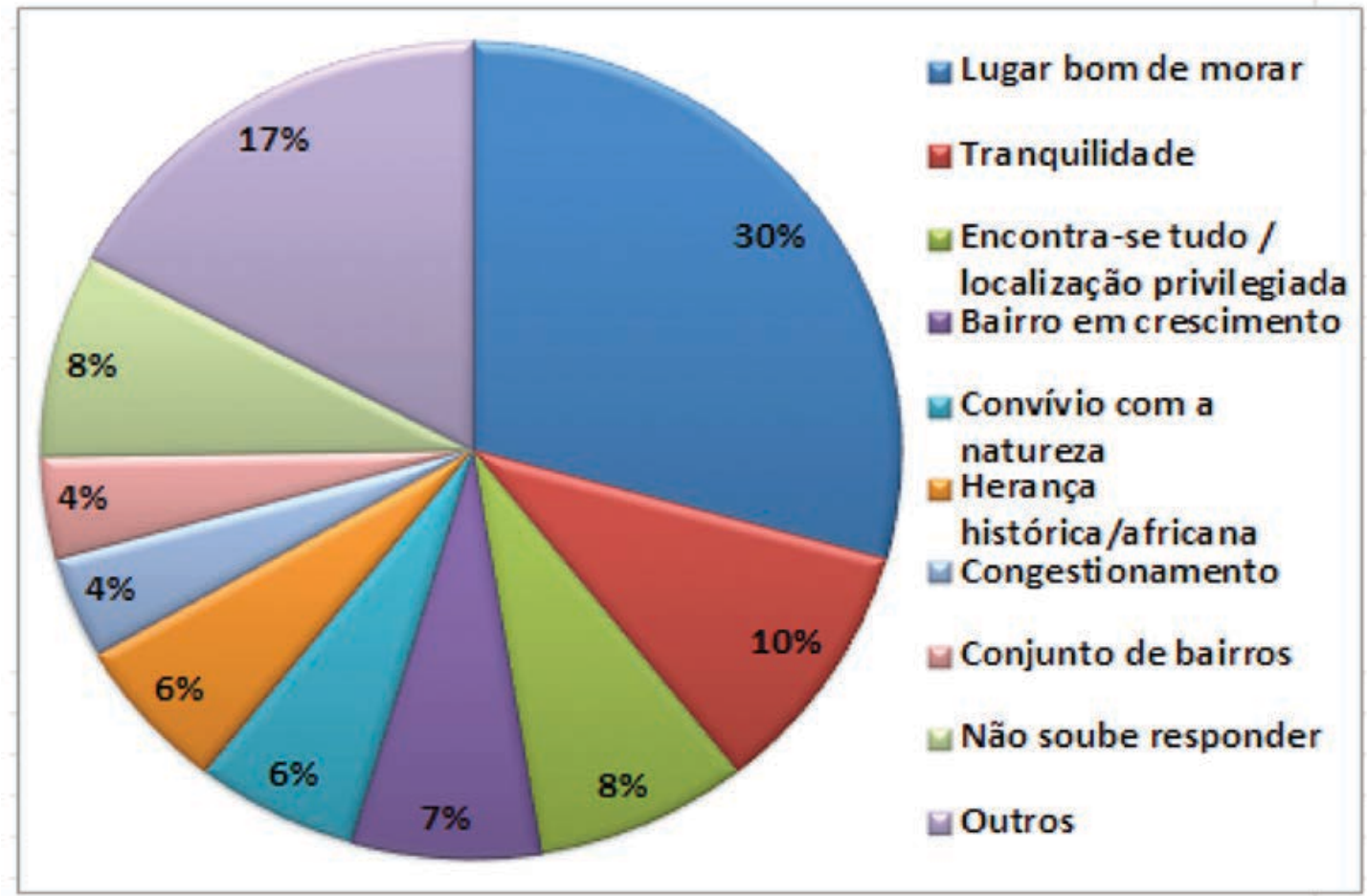

Figura 2 - 0 que pensa o entrevistado sobre a palavra Cabula

Fonte: Elaboração própria. Pesquisa de Campo - Maio/junho 2014

É interessante perceber que o termo "lugar" foi usado na maioria das respostas para classificar a palavra "Cabula", o que denota um alto nível de afetividade dos entrevistados para com o bairro ${ }^{14}$.

Uma possível implementação do TBC no Cabula foi considerada positiva para a comunidade e apresentou-se como uma esperança de aumento de renda. As pessoas acreditam no turismo como uma forma de transformar o bairro do Cabula em um local similar a outros bairros de turismo em Salvador para gerar status e melhora do poder aquisitivo.

13 Considerou-se o salário mínimo adotado no Brasil, no ano de 2014 , que era de $\mathrm{R} \$ 724,00$.

14 De acordo com Tuan (1983, p. 6), lugar é o "que começa como espaço indiferenciado transforma-se em lugar à medida que o conhecemos melhor e o dotamos de valor", essa constatação apresenta-se como um valor positivo para iniciativas comunitárias. 
Todavia, constatou-se ser necessário investir no estoque de conhecimento dos moradores sobre a história local. Os moradores pouco sabiam das relações culturais que envolvem o bairro, apesar de 84\% responderem conhecer a origem africana do nome, muitos outros aspectos eram desconhecidos, como o fato de ter se constituído em um importante quilombo da cidade de Salvador.

Esse papel histórico é pouco percebido no bairro contemporâneo, uma vez que $84 \%$ dos entrevistados alegaram não perceber nenhuma influência africana em seu cotidiano, fato que reforça a necessidade de incorporar esses elementos culturais ao cenário da cidade e ao dia a dia dos seus moradores.

Por outro lado, 57\% dos entrevistados afirmaram que "Gostariam de trabalhar com o patrimônio cultural de origem africana disponível no bairro". Os motivos para tal interesse são variados: "Gostam do tema" (34\%), "Querem ajudar a comunidade" (22\%), "Desejam melhorar a renda" (20\%), "Expandir o conhecimento" (11\%) entre outros (ver Figura 3).

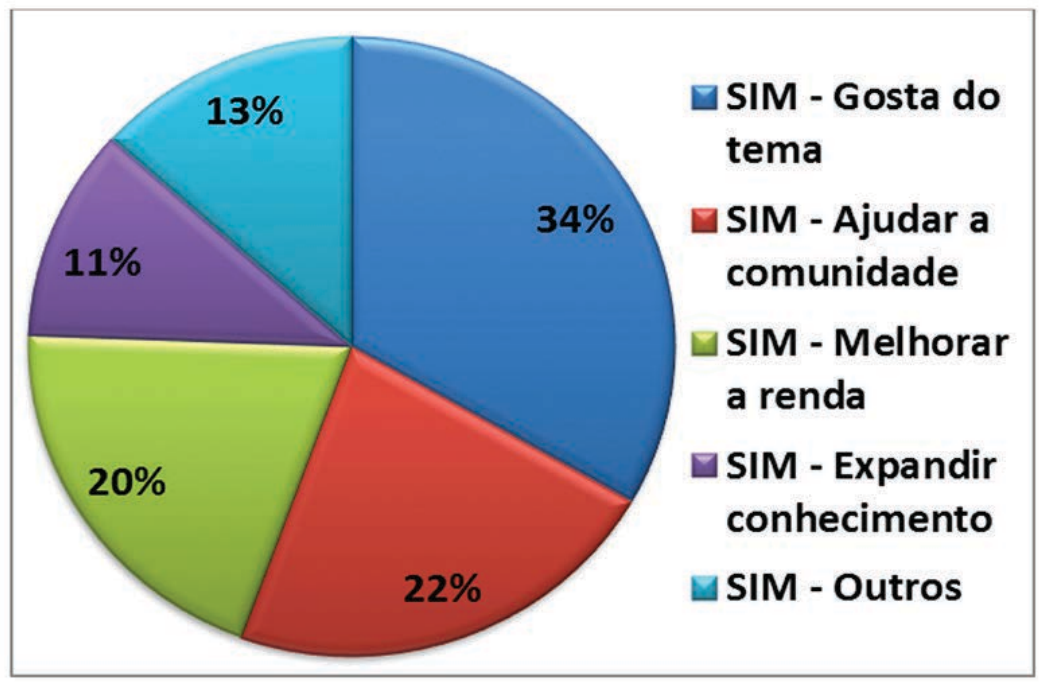

Figura 3 - Motivação para trabalhar com o patrimônio cultural de origem africana disponível no
seu bairro Fonte: Elaboração própria. Pesquisa de Campo - Maio/junho 2014

Na realidade é preciso que tal característica seja potencializada a partir de um cotidiano favorável. De acordo com Peres (2001), o investimento nesses estoques de conhecimentos pode ajudar a comunidade a desenhar seu próprio plano de crescimento.

Sobre o nível de afinidade da comunidade em relação ao trabalho com o turismo, $92 \%$ responderam saber do que se trata a atividade e $54 \%$ alegaram ter vontade de trabalhar com o turismo no bairro do Cabula. Na tentativa de identificar quais motivos levaram a maioria a dizer "sim", notou-se: "Melhorar a renda" (29\%), "Expandir conhecimento" (24\%), "Gostam do tema" (21\%), "Ajudar a comunidade" (19\%), conforme a Figura 4. 


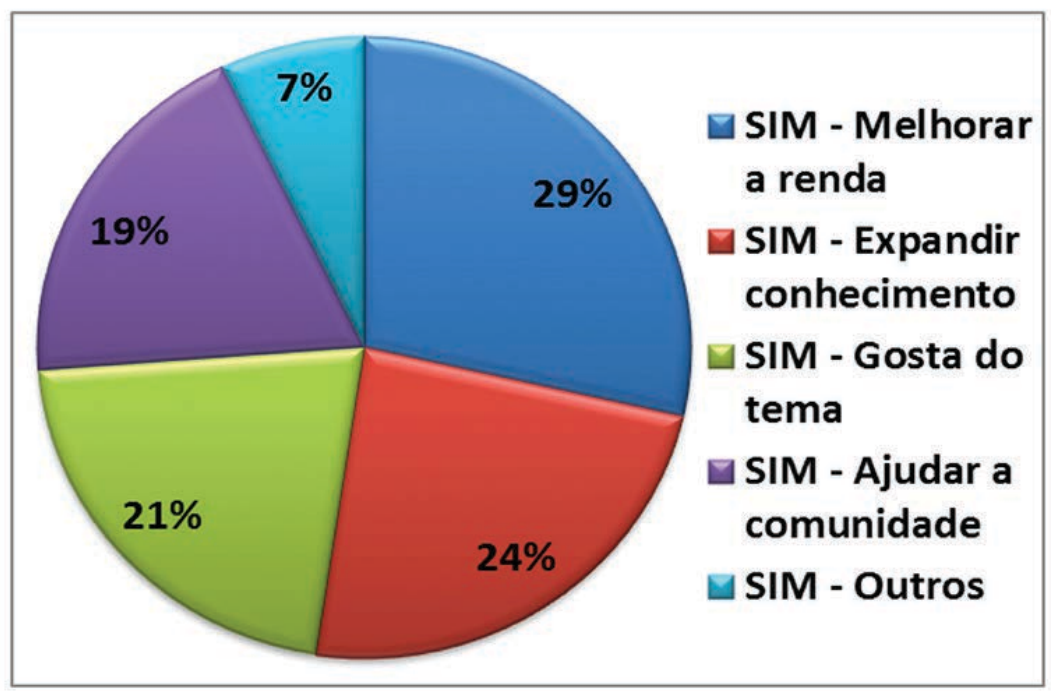

Figura 4 - Motivação para trabalhar com turismo

Fonte: Elaboração própria. Pesquisa de Campo - Maio/junho 2014

Ao comparar as respostas para as perguntas: “Gostariam de trabalhar com patrimônio cultural?" e "Gostariam de trabalhar com turismo?", percebeu-se que existe uma variação. De um lado, o trabalho com o patrimônio cultural representa para os entrevistados uma percepção relacionada ao "Gosto pessoal", a "Afinidade" e a "Relação com a comunidade". Do outro, o trabalho com o turismo foi associado diretamente a "Melhorar a renda", sendo essa percepção relativamente fixa em todos os momentos da pesquisa em que aparece o tópico turismo. No TBC, essas duas percepções devem estar associadas. O trabalhar com o turismo deve estar relacionado com a ideia de interação com a comunidade e com a identificação com o patrimônio local.

Dando prosseguimento, buscou-se identificar quais os níveis de confiança que os moradores nutriam em relação a seus vizinhos. Para tal, eles precisavam dizer se "concordavam" ou "não concordavam" com as afirmações abaixo, sendo as respostas, majoritariamente, positivas, conforme a Tabela 01.

Tabela 01 - Questões sobre os níveis de confiança

\begin{tabular}{|c|c|}
\hline QUESTIONAMENTOS & RESPOSTAS POSITIVAS \\
\hline "Pode-se confiar na maioria das pessoas que moram neste bairro" & $51 \%$ \\
\hline $\begin{array}{l}\text { "Neste bairro é preciso estar atento ou alguém pode tirar vantagem } \\
\text { de você" }\end{array}$ & $58 \%$ \\
\hline $\begin{array}{l}\text { "A maioria das pessoas neste bairro está disposta a te ajudar caso } \\
\text { você precise" }\end{array}$ & $65 \%$ \\
\hline $\begin{array}{l}\text { "Neste bairro as pessoas geralmente não confiam umas nas outras } \\
\text { quanto a emprestar e tomar dinheiro emprestado". }\end{array}$ & $32 \%$ \\
\hline
\end{tabular}

Fonte: Elaboração própria, 2014 
Todavia, a afirmação "Neste bairro as pessoas geralmente não confiam umas nas outras quanto a emprestar e tomar dinheiro emprestado", demonstra que essas mesmas relações, quando envolvem questões financeiras precisam ser mais cuidadosas. Nesse caso, ao surgir novas atividades econômicas no bairro, é necessário observar como é o comportamento dos atores envolvidos no gerenciamento de recursos (Figura 5).

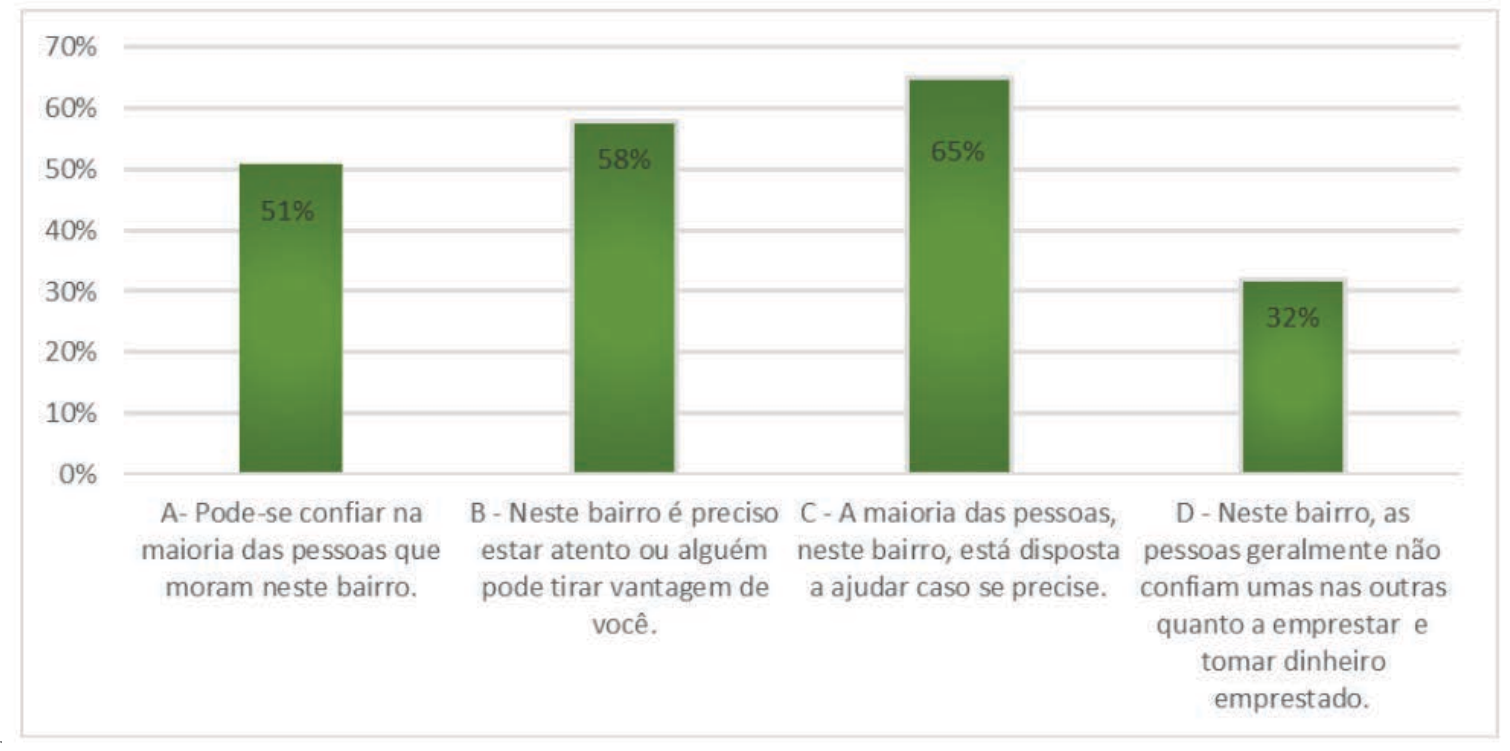

Figura 5 - Avaliação do nível de confiança dos moradores para as afirmações citadas

Fonte: Elaboração própria. Pesquisa de Campo - Maio/junho 2014

As questões que envolviam práticas de confiança nas instituições/grupos ou associações do bairro tiveram um alto grau de heterogenia. Ao serem indagados sobre "Você confia na(o) instituição X?" as respostas traduziram o cenário de interação e confiança da comunidade com as instituições locais. A "Universidade", em referência à Uneb, foi a instituição com maior expressividade, contando com a confiança de $80 \%$ dos entrevistados ${ }^{15}$. Em seguida os "Vizinhos" (66\%), "Comerciantes/Empresários locais" (64\%), "Médicos e Enfermeiros" (60\%), "Líderes Religiosos" (57\%) e com o menor estoque de confiança o "Poder Público de Gerenciamento do Turismo" com apenas 16\% (Figura 6).

15 Assume-se que isso se deve, em parte, ao já mencionado projeto de desenvolvimento de iniciativas de TBC desenvolvido por esta Universidade no bairro do Cabula, uma vez que esse tipo de ação implica no envolvimento comunitário dos professores e alunos envolvidos. 


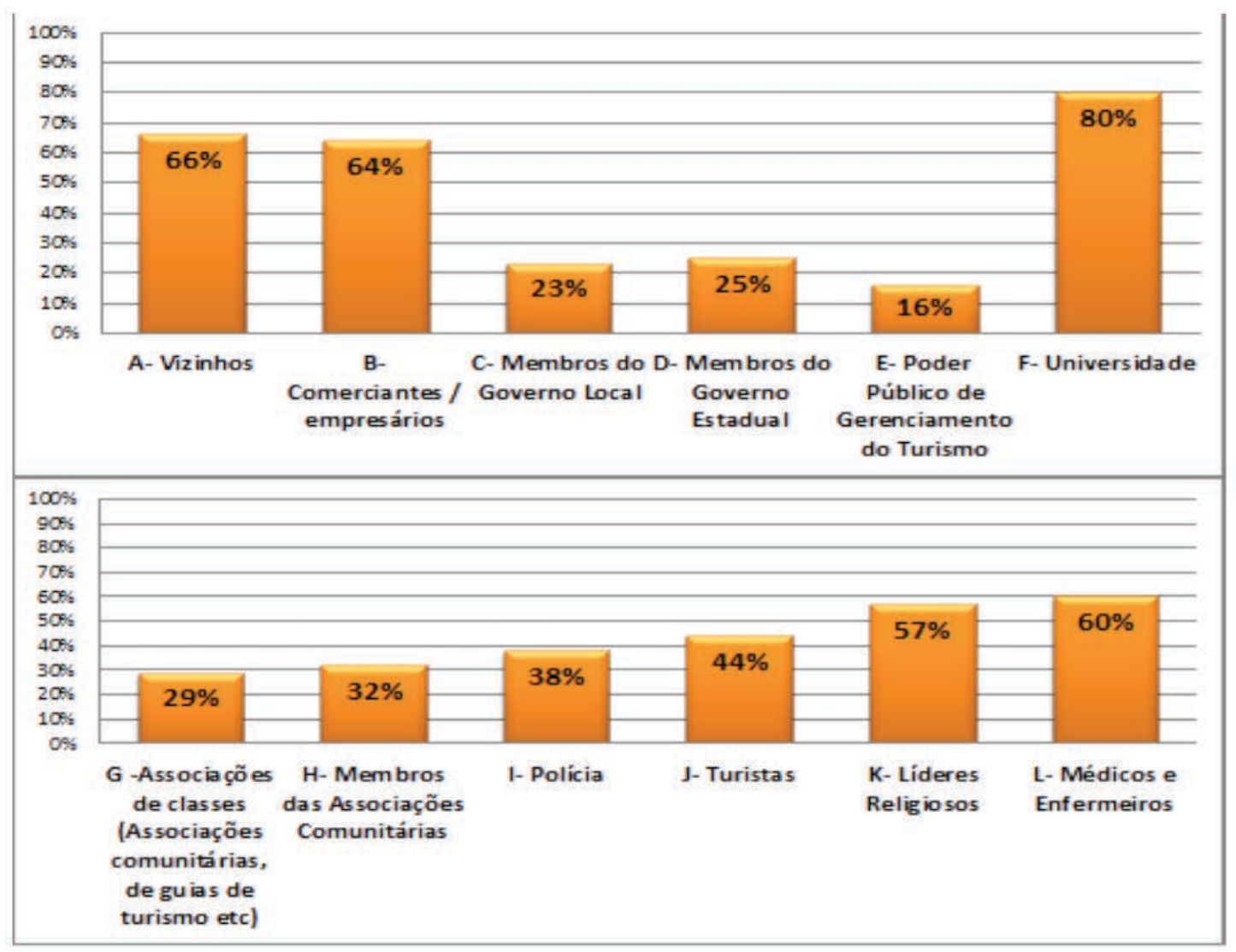

Figura 6 - Avaliação do nível de confiança dos moradores em grupos de atores citados

Fonte: Elaboração própria. Pesquisa de Campo - Maio/junho 2014

Acredita-se que por ser um bairro que não convive com o turismo, o "Órgão Público de Gerenciamento do Turismo" representa uma entidade distante da realidade dos moradores e por isso não desfruta do conhecimento/confiança dos entrevistados. Já os 32\% referentes aos "Membros das associações comunitárias" apresentam-se como um alerta. Isso porque essas associações comunitárias, apesar de representarem a comunidade, apresentam índices de confiança mais baixos que as instituições privadas.

A preocupação está pautada no fato de essas instituições locais, muitas vezes, serem as catalisadoras dos processos de interação e cooperação no âmbito das atividades econômicas propostas. E partindo do pressuposto que essa confiança é pequena, haverá a necessidade de buscar alternativas complementares. Segundo Cassiana, moradora do bairro há 38 anos, "essas relações foram desgastadas ao longo do tempo, pois já houve muito líder comunitário que só pensava em seu próprio bem e em sua melhora, esquecendo a comunidade". Ela continua dizendo que "no bairro seria necessário surgir uma nova liderança que fosse da própria comunidade e querida por todos para que as pessoas voltassem a acreditar em associação" (SILVA, 2014).

Quando indagados sobre "Como descreveria o grau de comunhão ou proximidade em seu bairro/ localidade?" eles responderam ser "Alto" e "Médio" (41\%). Ainda assim percebe-se que o nível de confiança não está sendo canalizado em ações concretas, pois identificou-se que $92 \%$ dos entrevistados 
não fazem parte diretamente e não possuem ninguém de sua família que participe de algum grupo, rede ou associação. Esse indicador é muito elevado e é necessário investigar as possibilidades de reversão ao mesmo tempo em que entender melhor os entraves que envolvem esse processo.

Percebe-se que apesar da demonstração de altos níveis de confiança entre si, os moradores não a exercitam através de uma prática comum. Essa informação, provavelmente, justifique o fato de que apenas $16 \%$ dos entrevistados tenham participado de alguma reunião de conselho, reunião aberta ou grupo de discussão; $6 \%$ de algum tipo de protesto e $10 \%$ de uma campanha eleitoral ou informativa. Apenas $12 \%$ desse público alegou ter alertado algum meio de comunicação sobre um problema local, enquanto 15\% notificaram a polícia ou a justiça sobre alguma questão da comunidade.

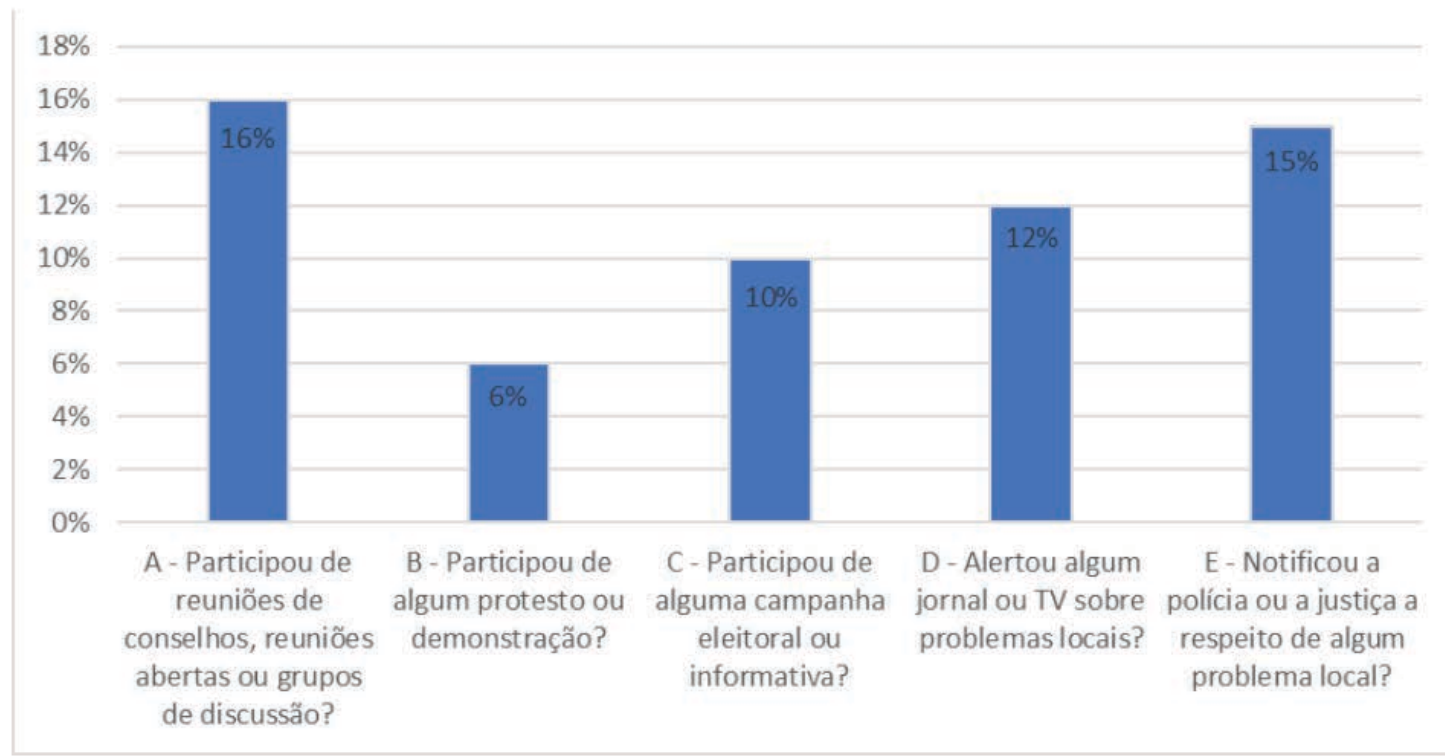

Figura 7 - Nível de engajamento dos moradores na resolução de questões locais Fonte: Elaboração própria. Pesquisa de Campo - Maio/junho 2014

Para se perceber melhor os sinais de cooperação mútua na comunidade, perguntou-se aos entrevistados se, caso um projeto da comunidade não lhe beneficiasse diretamente, mas trouxesse benefícios para muitas outras pessoas do bairro, se ele contribuiria com seu tempo ou dinheiro para o projeto, em que $76 \%$ dos entrevistados responderam afirmativamente.

Essa informação é relevante, pois as ações construídas visando a implantação de iniciativas participativas no turismo buscam a implementação de uma confiança que geralmente se constitui em um bem público, ao contrário do capital convencional que é tipicamente de caráter privado (SILVA, 2014). Na medida em que esses atores locais tiverem consciência de que exercem o protagonismo das suas ações, esse capital promove o empoderamento. Quanto mais horizontalizadas forem as estruturas de uma organização local, mais chances de êxito e de bom desempenho a comunidade terá.

Como visto, a importância do TBC em locais menos desenvolvidos ocorre como uma política afirmativa em direção à manutenção das tradições. O grande desafio do TBC é sustentar suas bases nas forças da população envolvida no processo, por meio das possibilidades locais de cultura e natureza, de modo a engajar a população nesses projetos turísticos (SILVA, 2014). 
Por mais que essas comunidades tenham interesse e percebam benefícios tangíveis na implantação de atividades como o TBC, é necessário ter consciência das suas limitações e dos principais desafios que precisam ser superados para o seu sucesso.

\section{Algumas reflexões de partida}

O TBC, como ficou demonstrado pelo referencial teórico apresentado, é um novo paradigma do "fazer" turístico, que se coaduna com os preceitos do desenvolvimento sustentável e endógeno. Como tal, traz novas oportunidades e desafios.

Ao ser uma proposta de turismo que tem como foco a redução da pobreza e das desigualdades sociais, por meio do fortalecimento dos laços comunitários e da noção de civismo e de pertencimento, o TBC aparece como uma alternativa desejável e aplicável em regiões menos desenvolvidas.

Todavia, também essa proposta de resolução, tal como o seu fato gerador, esconde um paradoxo: Como esperar que essas comunidades sejam protagonistas de seu próprio processo de desenvolvimento, se elas, na maioria das vezes, não possuem as condições necessárias para o exercício desse protagonismo?

Ao tentar responder a essa pergunta no âmbito do bairro estudado por este artigo, buscou-se identificar a existência de um produto turístico autêntico que possa ser oferecido por uma comunidade articulada e capaz de exercer o protagonismo dessa atividade, de acordo com as premissas trabalhadas para um projeto de TBC.

A herança africana aliada à riqueza natural dos remanescentes de mata se constituem nos principais patrimônios do bairro, ainda preservados pelos terreiros de candomblé e nas práticas musicais e manifestações artísticas. A relevância desse passado ensejou o desenvolvimento de um projeto de Turismo de Base Comunitária coordenado pela Universidade do Estado da Bahia, cujo campus localiza-se no bairro. O projeto ainda se encontra em fase de implantação, mas é a prova de que a exigência de atrativos autênticos é uma exigência parcialmente atendida, uma vez que ainda não se encontra sob o domínio da comunidade local que pouco conhece desse passado e suas representações.

O grande desafio encontrado na pesquisa para a implantação do TBC no bairro, contudo, diz respeito às duas últimas características. De acordo com as entrevistas realizadas, os laços de confiança existem entre os vizinhos e entre os respondentes e algumas instituições e atores, como a Uneb, os comerciantes locais, os médicos e líderes religiosos. Todavia, esse espectro de confiança não transcende a retórica, uma vez que permanece no campo das intenções e não foi possível perceber a sua materialização em ações coletivas como a participação em associações que representem os interesses comuns. Pelo contrário, segundo os respondentes, as associações não gozam da simpatia dos moradores, fato que dificulta a articulação comunitária em um primeiro momento.

O nível de engajamento, que mantém uma relação direta com o potencial de protagonismo dos atores locais, mostrou-se muito fraco. As questões locais não suscitam a atuação ativa dos respondentes perante a própria comunidade, os meios de comunicação ou o governo.

Por outro lado, existe uma grande disposição dos entrevistados para o trabalho na atividade turística associada ao patrimônio do bairro. Desejo fundamental para iniciar qualquer processo de mobilização comunitária em prol de atividades participativas como o TBC. 


\section{Referências}

ASHLEY, C.; GOODWIN, H. Pro poor tourism - what's gone right and what's gone wrong: UK: Overseas Development Institute Opinion 80. Jun. 2007 Disponivel em: 〈http://www.odi.org.uk/opinion/ docs/778.pdf>. Acesso em: 23 set. 2012.

BARQUERO, A. V. Desenvolvimento endógeno em tempos de globalização. Porto Alegre: Fundação de Economia e Estatística, 2002. 278 p.

DE KADT, E. Tourism: passport to development. London: Oxford University Press, 1979.

DOXEY, J. Development of tourism destinations. London: Torbay, 1975.

FERNANDES, M. R. Educação e formação em turismo. Aveiro - Portugal, 2005. Dissertação (Mestrado) - Universidade de Aveiro. p. 1-264.

FERNANDES, R. B. Las políticas de la vivienda en la ciudad de Salvador y los processos de urbanización popular en el caso del Cabula. Feira de Santana: Universidade Estadual de Feira de Santana, 2003.

GOMES, C. A. C. Entrevista I. [mar. 2014]. Entrevistador: Paulo Henrique Oliveira Silva. Salvador, 2014. 1 arquivo.mp3 (6o min.).

GOODWIN, H. Community-based tourism. Failing to deliver? Id 21 Insights. v. 62, june 2006. Disponível em: 〈http://www.mtnforum.org/sites/default/files/pub/4062.pdf〉. Acesso em: 21 set. 2015.

GOUVEIA, A. T. de A. Um olhar sobre o bairro: aspectos do Cabula e suas relações com a cidade de Salvador. 2010. Dissertação (Mestrado) - Universidade Federal da Bahia. Instituto de Geociências. Salvador, 2010.

GRANOVETTER, M. Economic action and social structure: the problem of embeddedness. American Journal of Sociology, v. 91, n. 3, p. 481-510, 1985.

MACCANNELL, D. Staged Authenticity: arrangements of social space in tourist settings. The American Journal of Sociology, v. 79, n. 3, p. 589-603, 1973.

The Tourist: a new theory of leisure class. Berkeley: University of California Press, 1976.

MARX, S. Community-based \& Pro-Poor Tourism: two contemporary approaches to poverty reduction in developing and least developed countries. 2011. Disponível em: 〈http://www.readperiodicals. com /201104/2479594071.html\#b\#ixzz29JgOqeGq〉. Acesso em: 1 out. 2012.

MATHIESON, A.; WALL, G. Tourism: economic, physical and social impacts, Harlow: Longman, 1982.

NICOLIN, J. de S. Arte bagaço odeart: ecos que entoam a mata africano-brasileira do Cabula. 2007. Dissertação (Mestrado) - Universidade do Estado da Bahia, Departamento de Educação, Campus I, Salvador, 2007.

PERES, F. C. O capital social como motor do desenvolvimento sustentável. Revista Marco Social, p. 24-31, 2001.

PLOG, S. Why destination areas rise and fall in popularity. In: KELLY, E. Domestic and International Tourism. Wellsbury: Institute of Certified Travel Agents, 1977.

POON, A. Tourism, Technology and Competitive Strategies. London: CAB, 1993. 
SANTOS, M. E. P. et al. (Org.). 0 caminho das águas em Salvador: bacias hidrográficas, bairros e fontes. Salvador: Ciags/Sema, 2010, v. 01, p. 1-486.

SCAGLIONE, M.; MARX, S.; JOHNSON, C. Tourism and Poverty Alleviation Approaches: a case study comparison. In: KELLER, P.; BIEGER, T. (Org.). Tourism Development after the Crises Global Imbalances. Poverty Alleviation, v. 5, Berlin. Erich Schmidt Verlag GmbH\&Co., 2011, p. 207-226.

SCHUDSON, M. Review Essay: on tourism and modern culture. American Journal of Sociology, v. 84, n. 5, p. 1249-1258, 1979.

SILVA, P. H. O. Cabula: um patrimônio disfarçado de Bairro - possibilidades de desenvolvimento territorial através de abordagens participativas do turismo. (Mestrado em Desenvolvimento Regional e Urbano) - Universidade Salvador, Salvador-BA. 2014.

Escola de educação percussiva integral: um exemplo de produção cultural no Cabula. Monografia (Graduação em Turismo e Hotelaria) - Universidade do Estado da Bahia. 2010.

ZAOUAL, H. Globalização e Diversidade Cultural. São Paulo: Editora Cortez. 2003.

. Nova economia das iniciativas locais: uma introdução ao pensamento pós-global. Tradução: Michel Thiollent. Rio de Janeiro: DP\&A Editora, 2006. 